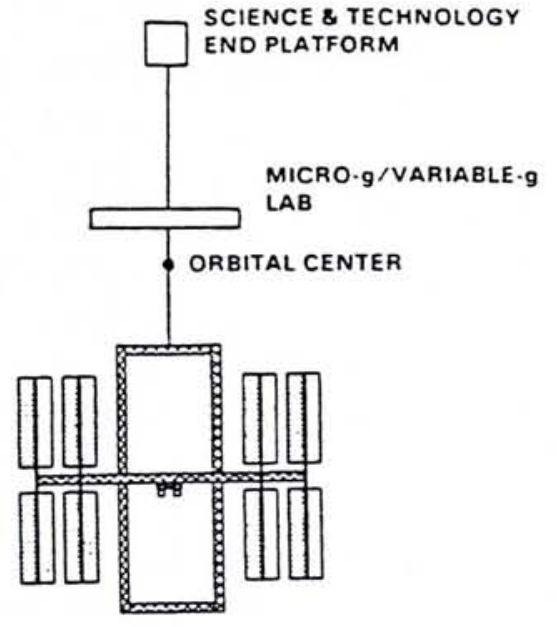

Fig. 6 - Multi-purpose experimental system with movable platform to control $\mathrm{g}$.

Below the ionospheric $F$ region, a variety of structures are to be studied, together with their temporal evolution at different scales.

\section{Geomagnetic and gravity surveys}

A definite possibility exists of using tethered satellites as platforms for making systematic high sensitivity surveys of geomagnetic and gravity anomalies. Satellite orbits are determined precisely by the actual gravity force field: the higher the orbit, the less the contribution from small scale features at ground or underground level. Information on small scale features requires the use of very low orbit satellites equipped with sensitive gradiometers: tethered satellites might be the right approach.

In-situ precise measurements of the geomagnetic field structure in the lower atmosphere, in addition to giving enlightenment on the characteristics of the ionospheric current system, will help to describe the field gradient, and thus to make fast and complete surveys of large and, above all, small scale features of internal sources. A similar improvement of knowledge is possible for the gravity field by using gravity gradiometers. Exact knowledge of the gravity field has fundamental importance in many areas. Among the various applications, solid Earth and ocean physics, Earth resources, satellite dynamical behaviour, inertial navigation can be mentioned. In particular, gravity anomalies associated with the motion of tectonic plates should be observable. Most large scale geophysical phenomena occurring at the surface of the Earth: earthquakes, volcanic phenomena, mountain build-up are in some way associated with anomalies of the density distribution below the surface down to several hundred $\mathrm{km}$, where they have their roots.

\title{
Space Challenge to European Students
}

To celebrate its silver Jubilee and to mark the launch of its two astronomical satellites, HST and Hipparcos, the European Space Agency (ESA) has organised an essay competition open to European students aged between 16 and 21. The main theme is "Astronomy from Space" and may comprise a comparison between space-based and terrestrial-based observations, an examination of the new fields opened by space-based telescopes, impact of space observations on science generally, a proposal for a specific experiment - no subject is barred. Length required is 2500 words maximum. One winner will be chosen for each Member State who will be invited to ESO H.Q. in Garching and three to five outstanding authors will be selected to visit the USA, or the Ariane launch centre in Kourou. Unfortunately closing date is 28 February so a rapid reaction is needed.

For further information ring ESA at ++ (33) (1) 42737155.

\section{Foreseeable Developments}

The number of scientific and technical applications being proposed for tethered satellites is continuously increasing. Generally speaking, unique capabilities of tethers are:

a) ability to deploy and retrieve over large distances masses connected to each other and hence practically unlimited capability for space transportation to or from space stations or other orbiting objects;

b)ability to produce a local controlled low gravity field, centred about an intermediate point between the two masses where the gravity is exactly zero;

c) possibility for a conducting tether to interact with the magnetic field of the Earth or other celestial bodies like the Sun, planets, etc., to make possible plasma research in unprecedented environments and even to produce energy;

d) possibility of momentum exchange between the two masses, by deploying or retrieving connected bodies.

Some typical examples of possible applications (selected from ref. [6]) are summarized in Figs. 6 and 7.

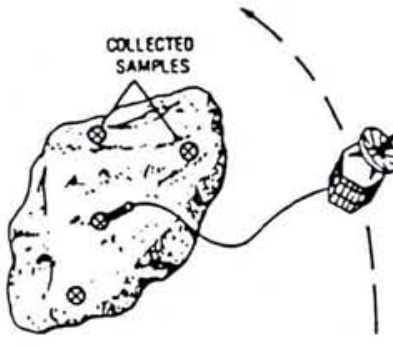

\section{RERERENCES}

(in chronological order)

Only a few individual papers are indicated. Rather, reference is made to recent general literature, in which other references can be found.

[1] Colombo G., Gaposchkin E.M., Grossi M.D., Smithson Astroph. Observ. Reports on Geoastronomy No. 1, Sept. 1974.

[2] The Tethered Satellite System, Final Report from the Facility Requirements Definition Team, May 1980 (NASA) 1980.

[3] Proc. Workshop on Applications of Tethers in Space, Williamsburg, Va. June $15-$ 17, 1983, Eds. P. Banks and C. Buongiorno (NASA) 1983

[4] Proc. Workshop on Applications of Tethers in Space, Venice October 15-17, 1985 Ed. W.A. Baracat (NASA CP 2422) 1986.

[5] Baracat W.A. and Butler C.L., Tethers in Space Handbook (NASA) 1986.

[6] Arnold D.A., op. cit. 35-50

[7] Tethers in Space, Proc. Int. Conf. Arlington, Sept. 17-19, Eds. P.M. et al., Advances in the Astronautical Sciences, 62 (1987).

[8] Laue J.H., Conference on Space Tethers for Science in the Space Station Era, Venice, October 1987.

[9] Proc. Tether Workshop, DFVLR KolnPorz, February 10, 1988, Ed. W. Seboldt.
Fig. 7-Sample collection from an asteroid for example [7]. 